repair. The preoperative and operative factors ${ }^{9-11}$ include "patient procrastination" and "inadequate operation" as reasons for recurrence. ${ }^{12}$ Postoperatively early mobilisation has been blamed for recurrence on the grounds of its conflict with the Hunterian principle that rest is the most useful aid a surgeon can bring to disordered tissues. ${ }^{13}$ Increasingly it has become apparent, however, that rest does not protect against recurrence but serves only to expose patients to the dangers of immobilisation.

Lichtenstein and Shore ${ }^{14}$ recently challenged many of the myths surrounding hernia repair and reported only a $0.9 \%$ recurrence rate despite encouraging immediate postoperative resumption of normal activity. An earlier study on the dynamics of wound healing had provided them with the rationale for permitting unrestricted postoperative activity. Using nonabsorbable sutures they showed that wounds achieved $70 \%$ of intact tissue strength immediately and were as strong at the completion of operation as after two months' healing. ${ }^{15}$ The use of a nonabsorbable suture is essential to maintain tissue strength during healing. Palumbo and Sharpe ${ }^{16}$ have also shown that early ambulation does not provoke recurrence: they reported both lower morbidity and a lower recurrence rate in patients mobilised on the first day, compared with those kept in bed for ten days. The excellent results achieved at the Shouldice clinic ${ }^{3}$ provide further proof: there patients are encouraged to return to normal activity immediately, and many return to work during the next week. Stevedores and lumberjacks are advised to wait four weeks. ${ }^{17}$

Attempting to answer the patient's question "How long should I stay off work ?" Ross ${ }^{18}$ has argued that patient activity is restricted for far too long in British practice and that four weeks' absence should be the maximum. No correlation exists between time off work and recurrence rate, ${ }^{18}$ and heavy work does not jeopardise the results of herniorrhaphy. ${ }^{9}$ There is no evidence to justify the belief that patients should refrain from work for six months after herniorrhaphy." "Traditions die hard and some medical ones seem to take an unconscionable time to do so." 17

The average hospital stay of 10.5 days after herniorrhaphy ${ }^{19}$ is therefore neither necessary nor justifiable, and the knowledge that postoperative activity does not jeopardise herniorrhaphy should encourage early discharge. Farquharson ${ }^{20}$ pioneered outpatient herniorrhaphy with no deterioration in results, and the advantages of outpatient ${ }^{21-24}$ and short stay herniorrhaphy ${ }^{31925}$ have been repeatedly reaffirmed. The effective management of patients with hernias can be combined with more efficient use of hospital facilities with a reduction in the overall cost to the community. Hospital savings do not become community costs. ${ }^{13}$

1 Wakeley, C P G, Lancet, 1940, 1, 822.

2 Zimmerman, L M, and Anson, B J, Anatomy and Surgery of Hernia, 2nd ed. Baltimore, Williams and Wilkins, 1967.

${ }^{3}$ Glassow, F, Annals of the Royal College of Surgeons of England, 1976, $58,133$.

4 Brandon, W J M, Lancet, 1958, 1, 637.

5 Ellis, H, British fournal of Hospital Medicine, 1970, 4, 9.

${ }^{6}$ Lichenstein, I L, Hernia Repair Without Disability. St Louis, C V Mosby, 1970.

${ }^{7}$ Koontz, A R, in Hernia, eds L M Nyhus and H N Harkins, p 227. London, Pitman Medical, 1964.

8 Glassow, F, British Medical fournal, 1970, 1, 215.

${ }^{9}$ Marsden, A J, British fournal of Surgery, 1962, 49, 384.

10 Maingot, R, Abdominal Operations, 6th ed. New York, Appleton, Century, Crofts, 1974.

11 Weinstein, M, and Roberts, M, American fournal of Surgery, 1975, 129, 564.

12 Zimmerman, L M, Surgical Clinics of North America, 1971, 51, 1317. ${ }_{13}$ Simpson, J E P, British fournal of Hospital Medicine, 1976, 16, 571.
14 Lichtenstein, I L, and Shore, J M, American fournal of Surgery, 1976, 132, 307.

${ }^{15}$ Lichtenstein, I L, et al, Surgery, Gynecology and Obstetrics, 1970, 130, 685.

16 Palumbo, L T, and Sharpe, W S, Surgical Clinics of North America, 1971, 51, 1293.

1: Iles, J D H, Fournal of the American Medical Association, 1972, 219, 385. is Ross, A P J, Annals of the Royal College of Surgeons of England, 1975, 57, 326.

19 Doran, F S A, White, M, and Drury, M, British fournal of Surgery, $1972, \mathbf{5 9}, 333$

20" Farquharson, E L, Lancet, 1955, 2, 517.

${ }^{21}$ Ruckley, C V, et al, Lancet, 1973, 2, 1193.

22 Stephens, F O, and Dudley, H A F, Lancet, 1961, 1, 1042.

${ }^{23}$ Kornhall, S, and Olsson, A M, American fournal of Surgery, 1976, 132, 32.

${ }^{24}$ Williams, J A, British Medical fournal, 1969, 1, 174

${ }^{25}$ Morris, D, Ward, A W M, and Handyside, A J, Lancet, 1968, 1, 681.

\section{Pathological fractures: cement and internal fixation}

When the clinical issues at stake are high doctors find their cherished freedom to exercise clinical choice in action proportionately less comforting. Few such decisions are more difficult than those encountered in patients with pathological fractures from metastatic cancer. The difficulty is further accentuated by the relative infrequency of these fractures in an average orthopaedic surgeon's experience. ${ }^{1}$ In such circumstances recourse to the library should be a reflex, and December 1976 issue of the Fournal of Bone and Foint Surgery ${ }^{2-4}$ is rewarding. A series of major papers there reviews results in almost 500 patients from North America. The prime study is on the use of methyl methacrylate cement as an adjunct to intramedullary nail fixation, thus overcoming the instability from wide resection of bone defects. As many as $94^{\circ} \%$ of patients could walk again after the completion of the procedure. Whether the prognosis might be excellent (as in metastatic breast carcinoma) or poor (as in some of the rare multiple lytic lesions) we now have the means to restore good physical activity.

Today, when the concept of audit has a foothold in the daily press, doctors should be even more willing to publish the results of treatment so that others can study soundly based guide lines rather than mere analyses of national practices in, for instance, the duration of inpatient care. These American articles highlight another economic consideration to be added to our present financial pressures. At a time when the orthopaedic surgeons most skilled in bonding metal to bone by cement are already facing ever-lengthening waiting lists for prosthetic replacement of arthritic joints, they now must add another urgent group to the queue: those needing treatment of pathological fractures. The size of this group is unknown, as some surgeons include in their data a proportion of prophylactic resections and cement nailing. Some surgeons ${ }^{4}$ include the ordinary senile fracture of the neck of the femur as pathological. Such injuries are also being treated by metal and cement replacement in some hospitals.

Another aspect of these new techniques is that many patients now return to the surgeon with a recurrence of the cancer that he had treated months or years before, and hence there is the element of unwelcome evidence of the failure of primary surgery. Patient and surgeon are forced to acknowledge the realities of the prognosis; but there will be instances in which a surgeon's almost impossible attempt to restore function may still be justified as giving the patient new hope during his final failing weeks. Three months' life expectancy should be 
considered as a reasonable indication for the benefit to be had from intramedullary nailing with cement. Not only is action welcome in outwardly hopeless circumstances, but these procedures also give good relief of pain.

Nowadays most sufferers from malignant disease expect to share the truth of their plight, and some degree of individual choice has become seen as a patient's right. Pathological fracture never lent itself to the otherwise occasionally useful "copper bottomed lie" approach to cancer described by Sir Heneage Ogilvie. Spontaneous abnormal mobility of a limb is not easily explained away, and the American articles ${ }^{2-4}$ give good advice on the humane and effective action.

' Sweetman, R, Clinical Orthopaedics, 1975, 111, 57.

2 Douglass, H O, Shukla, S K, fournal of Bone and foint Surgery, 1976, 58A, 1055.

${ }^{3}$ Harrington, K D, et al, fournal of Bone and foint Surgery, 1976, 58A, 1047.

- Zickel, R E, and Mouradian, W H, Fournal of Bone and foint Surgery, 1976, 58A, 1061

5 Stewart, I M, British Medical fournal, 1957, 2, 922.

\section{Perforating diverticulitis}

For many years the orthodox management of perforating diverticulitis was a multistage procedure of colostomy followed by elective resection and colostomy closure. More recently, this approach has come under increasing criticism for its high mortality and morbidity. ${ }^{12}$ The alternative, aggressive operation of emergency resection may now have become the treatment of choice. ${ }^{3}$ Review of recent experience in Britain and America shows that not more than $25^{\circ}{ }_{0}$ of operations for diverticulitis are done for acute perforation. ${ }^{4-7} \mathrm{~A}$ single district hospital might have only three to five such emergency operations a year: in the Birmingham region, for example, with its five-million population, between 1969 and 1973 there were on average 65 operations a year for acute perforated diverticulitis. ${ }^{1}$ Most cases are still managed conservatively.

Diagnosis of perforating diverticulitis may be difficult. In a recent account of 30 cases eight had come under the care of gynaecologists; six cases had been diagnosed as appendicitis, and two as carcinoma. ${ }^{8}$ Such a scatter seems commonplace: less than half of the patients give a history that would give any guide to the correct diagnosis. These difficulties in diagnosis must lead to many patients having a laparotomy when, had the correct diagnosis been made, emergency surgery might not have been undertaken.

Several different pathological conditions come under the general heading of perforating diverticulitis, and they need to be distinguished if our treatment policies are to be rational. Firstly, the patient may have an area of localised inflammation - to use an old-fashioned expression, a phlegmon of the colon - or he may have a walled-off-abscess, either pericolic or intramesenteric. If the diagnosis is reasonably certain the patient may be treated conservatively with intravenous fluids and broad-spectrum antibiotics, in much the same way as for an appendix abscess. In most patients the acute condition will settle down, and they may then be assessed at leisure and a decision made on whether elective surgery is needed. If there are no contraindications to major surgery and the episode has been the culmination of a long history of trouble from diverticulitis, then resection should be advised. If the acute attack was the first evidence of the disease then it seems reasonable to await further developments.
The second group of conditions are those producing a free perforation. This may be large, giving rise to gross severe faecal peritonitis, or small, allowing the escape of only gas and bacteria, producing a much less severe bacterial peritonitis. In either case laparotomy is required. If the perforation is small with bacterial peritonitis only, management may be limited to simple drainage of the site of the perforation, with appropriate antibiotic cover. The surgeon may be able to seal the small perforation with omentum or adjacent appendices epiploicae, but this is by no means always simple. Whether a transverse colostomy should be added is debatable: it is probably safe not to do so but the evidence is not yet conclusive.

The patients with faecal peritonitis are at greatest hazard: mortality rates may be as high as $20 \%$ and $40 \%{ }^{12}$ This gloomy outlook reflects a combination of adverse factors. Most patients are elderly and have other medical problems, and they tend to come in late in the course of their illness. Furthermore, transverse colostomy and simple drainage has often proved ineffective in treating the condition: this method fails to remove the continuing source of faecal contamination between the colostomy and the perforation. The surgical procedure of choice in these patients is becoming resection of the diseased bowel, bringing the proximal descending colon out as a terminal colostomy (combined with copious peritoneal lavage with saline and antibiotic cover), for primary anastomosis after resection carries an unacceptably heavy mortality and morbidity. Nevertheless, while resection may now be the treatment of choice, it is no task for a junior registrar with an SHO anaesthetist in the middle of the night. An experienced team is essential.

1 Localio, S A, and Stahl, W M, Current Problems in Surgery, p 20. Chicago, Year Book Medical Publishers, 1968.

2 Madden, J L, and Tan, P Y, Surgery, Gynecology and Obstetrics, 1961, 113, 646.

${ }^{3}$ Williams, J A, Diseases of the Colon and Rectum, 1976, 19, 289.

${ }^{4}$ Miller, D W, and Wichern, W A, American fournal of Surgery, 1971, 121, 536.

${ }^{5}$ Colcock, B P, American fournal of Surgery, 1968, 115, 264.

${ }^{6}$ Giffin, J M, Butcher, H R, and Ackerman, L V, Archives of Surgery, $1967,94,619$.

7 Watkins, G L, and Oliver, G A, Surgery, 1971, 69, 215.

${ }^{8}$ Sweatman, C A, and Aldrete, J S, Surgery, Gynecology and Obstetrics, $1977,144,47$.

\section{Whooping-cough immunisation}

During the past two decades pertussis has become both much less common and much less life-threatening than in the early part of the century and between the two world wars. Even so, outbreaks still occur, and among the most recently studied (and most notable because of its size) was that of 1974-5. On that occasion the mortality for notified cases under 6 months of age was still high ${ }^{1}$; when there was no threat to life many affected babies were in hospital for long periods, while persistent cough and wheeze continued after the acute phase had passed. Nor should outbreaks be the only cause for concern: in the interval between them the disease remains endemic, with 3000-4000 notifications each year.

The prevention of whooping cough has therefore much to commend it. Extensive vaccine trials were carried out in Britain in the 1950s, and studies were also undertaken to determine the best time in the first year of life to start immunisation and the optimum interval between doses. Maternal antibody against pertussis was found not to be 